\title{
Polymorphic ventricular tachycardia after radiofrequency maze procedure: Report of two cases
}

\author{
Santosh Kumar Dora, DM, ${ }^{\text {a }}$ Praveen Kerala Varma, Mch, ${ }^{\text {b }}$ \\ Chandrabhanu Parija, MS, ${ }^{\text {b }}$ Krishnakumar Nair, DM, ${ }^{\text {a }}$ Rupa Sreedhar, MD, ${ }^{c}$ \\ Kurur Sankaran Neelakandhan, Mch, ${ }^{\mathrm{b}}$ and Jaganmohan Tharakan, $\mathrm{DM}^{\mathrm{a}}$ \\ Kerala, India
}

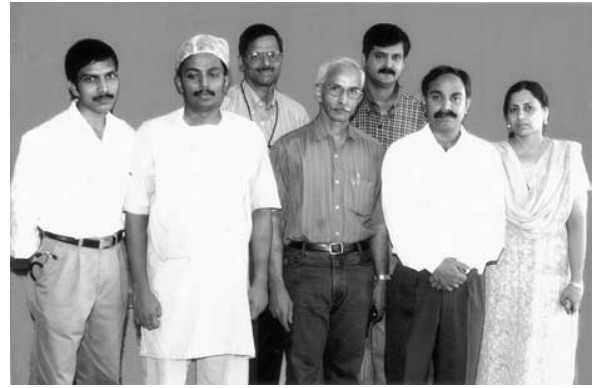

Parija, Nair, Neelakandhan, Dora, Sreedhar (front row, left to right); Tharakan, Varma (back row, left to right) ince the initial report in 1991, the maze procedure performed surgically (cut and sew) has been widely accepted worldwide as a treatment for atrial fibrillation (AF) with or without associated structural heart disease. ${ }^{1,2}$ In an effort to reduce the number of incisions, an irrigated radiofrequency (RF) device has been used to create the majority of the required lesions. ${ }^{3}$ We report postoperative sinus node dysfunction complicating polymorphic ventricular tachycardia (VT) in 2 patients who underwent the maze procedure by means of RF ablation along with valve replacements.

\section{Clinical Summary}

PATIENT 1. A 46-year-old woman with rheumatic heart disease with severe calcific mitral stenosis and AF underwent the biatrial maze III procedure with saline-irrigated, cooled-tip- RF ablation (SICTRA; Medtronic Cardioblate System, Medtronic Inc) and mitral valve replacement with a $27-\mathrm{mm}$ Medtronic Hall mechanical valve. Postoperatively, there was no sinus activity, and the patient was in junctional escape rhythm at a rate of 35 beats/ min (Figure 1). The QTc interval of the junctional escape rhythm was $600 \mathrm{~ms}$, and there were frequent ventricular ectopics caused by early postdepolarization. The patient was paced at a rate of 90 beats/min with epicardial pacing wires. On the third postoperative day, the epicardially placed pacing wires failed to function. On the same day, the patient had multiple episodes of polymorphic VT (Figure 2), which were DC cardioverted. Subsequently, a transcutaneous temporary pacemaker was implanted and paced at 90 beats/min. Because of the persistence of slow junctional rhythm and the absence of sinus activity even after 1 week of the procedure, a ventricular-based permanent pacemaker (Medtronic SS103, Medtronic Inc) was implanted and paced at 90 beats/min.

\footnotetext{
From the Divisions of Cardiology, ${ }^{\mathrm{a}}$ Cardiothoracic Surgery, ${ }^{\mathrm{b}}$ and Anesthesiology, ${ }^{\mathrm{c}}$ Sree Chitra Tirunal Institute for Medical Sciences and Technology, Kerala, India.

Received for publication May 4, 2004; accepted for publication May 21, 2004.

Address for reprints: Santosh Kumar Dora, DM, Division of Cardiology, Sree Chitra Tirunal Institute for Medical Sciences and Technology, Trivandrum, Kerala, India-695 011 (E-mail: kskdora@sctimst.ker.nic.in).

J Thorac Cardiovasc Surg 2005;129:446-7

$0022-5223 / \$ 30.00$

Copyright $\odot 2005$ by The American Association for Thoracic Surgery

doi:10.1016/j.jtcvs.2004.05.026
}

PATIENT 2. A 43-year-old woman with rheumatic heart disease, severe mitral regurgitation, mild mitral stenosis, severe aortic regurgitation, and $\mathrm{AF}$ underwent the biatrial maze III procedure by using RF ablation (SICTRA; Medtronic cardioblate system, Medtronic Inc) and mitral (28-mm Starr-Edwards prosthesis, Edward Life Sciences) and aortic valve (21-mm TTK-Chitra; TTKPharma) replacements. After the operation, the patient was in junctional rhythm, with a rate of 36 beats/min and no sinus activity. The QTc interval was $580 \mathrm{~ms}$, and there were frequent early postdepolarizations. On the 19th postoperative day, after loss of pacing through epicardial pacing wires, the patient experienced polymorphic VT, which was DC cardioverted. Because of the absence of sinus rhythm and the presence of slow junctional rhythm with a prolonged QT interval even after 3 weeks, a permanent pacemaker (Biotronik Pikos 01, Biotronik GmbH \& Co) was implanted and paced at 90 beats $/ \mathrm{min}$.

\section{Discussion}

During the initial years of the maze procedure, 2 complications were frequently encountered: sinus node dysfunction with predominantly blunted chronotropic response and left atrial mechanical dysfunction, for which the maze I procedure has been modified 2 times to the presently well-accepted maze III procedure. ${ }^{4}$ Even in the maze III procedure transient sinus node dysfunction persisting up to 1 year has been reported. ${ }^{5}$ The polymorphic VT as a consequence of slow junctional escape rhythm caused by sinus node dysfunction after the maze procedure has not been reported. Bradycardia-related polymorphic VT is well documented in patients with drug-refractory AF undergoing RF ablation of the atrioventricular node. ${ }^{6,7}$ The resulting long QT interval has been responsible for the triggered activity-mediated VT and proved experimentally to be due to downregulation of both rapid and slowly activating components of delayed rectifier potassium current in association with altered L-type calcium current. ${ }^{8}$ Increased sympathetic nervous activity is also responsible for the tachyarrythmia state after RF ablation of the atrioventricular node. ${ }^{9} \mathrm{RF}$ ablation leads to tissue dessication caused by the resistive heat and destroys the underlying tissue to cause linear scarring. However, it might affect the surrounding tissue also, making these lesions not so linear. Direct sinus node injury caused by RF ablation is less likely because the RF lines in the right atrium were away from the sinus node position. However, because the sinus node position is not fixed and might vary minimally from person to person, conducted heat from the lesions extending from the superior vena cava to the inferior vena cava might have caused sinus node damage in these 2 cases. 


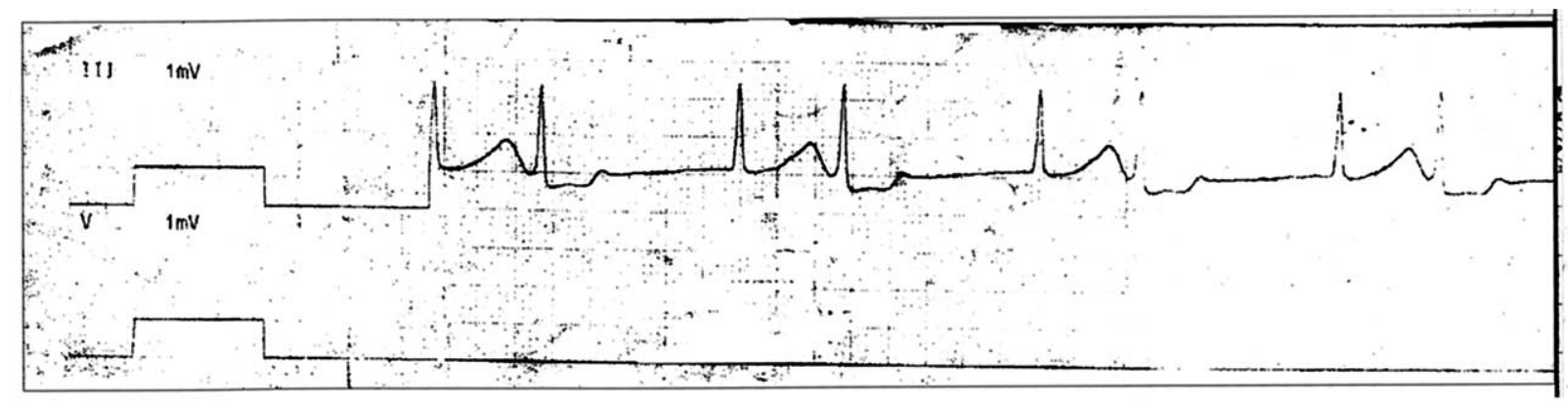

Figure 1. Postoperative cardiac rhythm: junctional rhythm with long OT interval and early postdepolarization in bigeminal pattern.

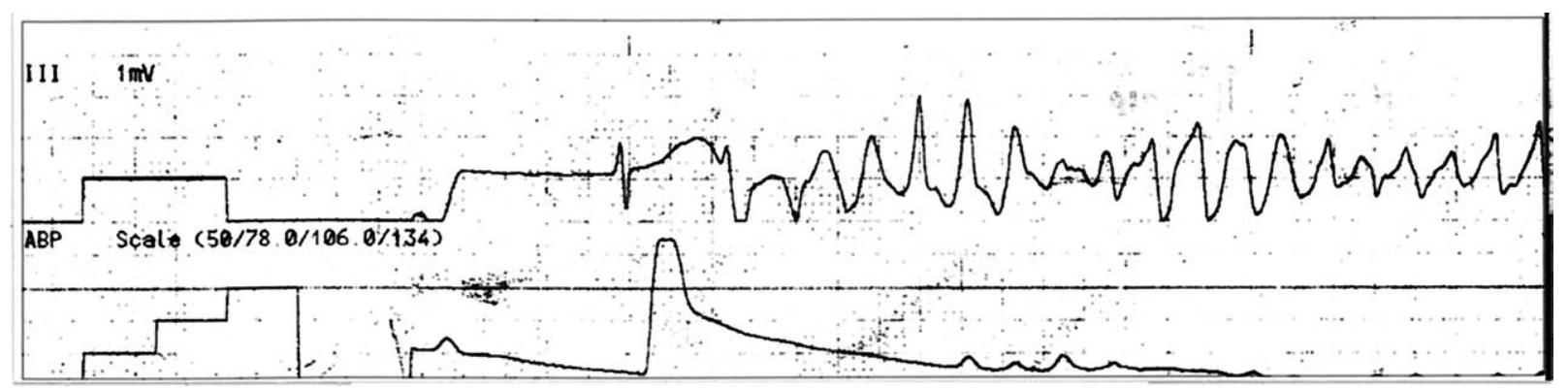

Figure 2. Polymorphic VT after the junctional beat. No recordable blood pressure was seen during the VT.

\section{Conclusion}

Bradycardia after the maze procedure caused by sinus node dysfunction might give rise to long QT intervals mediated early after depolarization, which could lead to polymorphic VT. If sinus node dysfunction-related bradycardia persists during the postoperative period, close monitoring is needed for the possibility of any malignant arrhythmia. In these cases a prophylactic permanent pacemaker implantation might be advised to avoid the risk of sudden cardiac death at follow-up.

\section{References}

1. Cox JL. Surgical treatment of atrial fibrillation. IV. Surgical technique. J Thorac Cardiovasc Surg. 1991;101:584-92.

2. Isobe F, Kawashima Y. The outcome and indications of the Cox maze procedure for chronic atrial fibrillation with mitral valve disease. J Thorac Cardiovasc Surg. 1998;116:220-7.

3. Sie HT, Beukema WP, Elvan A, Ramdat Misier AR. Long term results of irrigated RF modified maze procedure in 200 patients with concomitant cardiac surgery: six years experience. Ann Thorac Surg. 2004;77(2):512-7.
4. Cox JL, Boineau JP, Schuessler RB, Jaquiss RD, Lappas DG. Modification of the maze procedure for atrial flutter and atrial fibrillation. I. Rationale and Surgical results. J Thorac Cardiovasc Surg. 1995;110: 473-84.

5. Pasic M, Musci M, Siniawski H, Edelmann B, Tedoriya T, Hetzer R. Transient sinus node dysfunction after the Cox-maze III procedure in patients with organic heart disease and chronic fixed atrial fibrillation. J Am Coll Cardiol. 1998;32:1040-7.

6. Azar RR, Lippman N, Kluger J. Recurrent polymorphic ventricular tachycardia complicating RF catheter ablation of the atrioventricular junction. PACE. 1998;21:1837-40.

7. Nowinski K, Gadler F, Jensen-urstad M, Bergfeldt L. Transient polymorphic state following atrioventricular junctional RF ablation. PACE. 2002;25:291-9.

8. Tsuji Y, Opthof T, Yasui K, Inden Y, Takemura H, Niwa N, et al. Ionic mechanisms of acquired QT prolongation and torsades de pointes in rabbits with chronic complete atrioventricular block. Circulation. 2002; 106:2012-8

9. Hamdan MH, Page RL, Sheehan CJ, Zagrodzky JD, Wasmund SL, Ramaswamy K, et al. Increased sympathetic activity after atrioventricular junction ablation in patients with chronic atrial fibrillation. $J$ Am Coll Cardiol. 2000;36:151-8. 